\title{
Salivary IgA as a Useful Biomarker for Dental Caries in Down Syndrome Patients: A Systematic Review and Meta-analysis
}

\author{
Hiba Hamid ${ }^{1, \odot}$ Necdet Adanir ${ }^{2, \subseteq}$ \\ Faris Yahya Ibrahim Asiri ${ }^{3}$ \\ Zohaib Khurshid ${ }^{7}$ \\ ${ }^{1}$ Department of Oral Biology, Liaquat College of Medicine \& \\ Dentistry, Karachi, Pakistan \\ ${ }^{2}$ Department of Restorative Dentistry, College of Dentistry, King \\ Faisal University, Al Ahsa, Saudi Arabia \\ ${ }^{3}$ Department of Preventive Dentistry, College of Dentistry, \\ King Faisal University, Al Ahsa, Saudi Arabia \\ ${ }^{4}$ Department of Biostatistic, College of Physicians and Surgeons \\ Pakistan, Karachi, Pakistan \\ ${ }^{5}$ Department of Restorative Dentistry, College of Dentistry, \\ Taibah University, Medina, Saudi Arabia \\ ${ }^{6}$ Department of Dental Materials, Islamic International Dental \\ College, Riphah International University, Islamabad, Pakistan \\ ${ }^{7}$ Department of Prosthodontics and Dental Implantology, College \\ of Dentistry, King Faisal University, Al Ahsa, Saudi Arabia
}

Khadijah Abid ${ }^{4}$ Muhammad Sohail Zafar ${ }^{5,6, \odot}$

\begin{abstract}
Address for correspondence Zohaib Khurshid, MRes, MDTFEd, FPFA, BDS, Department of Prosthodontics and Dental Implantology, College of Dentistry, King Faisal University, Al Ahsa 31982, Saudi Arabia (e-mail: drzohaibkhurshid@gmail.com).
\end{abstract}

Eur J Dent:2020;14:665-671

\begin{abstract}
The objective of this systematic review and meta-analysis is to critically analyze and summarize studies reporting association of salivary immunoglobulin $A(\operatorname{lgA})$ levels as a biomarker for dental caries in Down syndrome (DS) patients. Using the keywords salivary [All Fields] AND IgA [All Fields] AND ("down syndrome" [MeSH Terms] OR ("down"[All Fields] AND "syndrome" [All Fields]) OR "down syndrome" [All Fields]), an electronic search was conducted via PubMed and Scopus databases by two authors, H. H. and Z. K. independently. Retrieved studies were screened against the predefined exclusion and inclusion criteria. To estimate the risk of bias, quality assessment of included studies was carried using the Newcastle-Ottawa quality assessment scale for observational studies. Primary search resulted in 10 articles from PubMed and 13 articles from Scopus. Ten studies fulfilled the defined selection criteria and evaluated the salivary $\lg A(s \lg A)$ level in DS patients with dental caries. Five articles were further analyzed in a quantitative synthesis presented in the meta-analysis. Due to a modified lifestyle and compromised oral hygiene in DS patients, understandably, it is still postulated in the literature that the presence of slgA can have a protective effect on the occurrence of dental caries as

Keywords

- saliva

- dental caries

- salivary IgA

- Down syndrome compared with healthy counterparts. As indicated by the present meta-analysis, no conclusions can be drawn as to definitively label sigA as a biomarker for dental caries. Further, well-designed longitudinal clinical studies and translational research are therefore required before the benchmarking of slgA as a useful biomarker for dental caries in DS patients with preferable molecular insights.
\end{abstract}

\section{Introduction}

Down syndrome (DS) is one of the most prevalent genetic disorders occurring among humans resulting from a trisomy of chromosome 21. The incidence of DS is estimated to be around 1 in 1,000 to 1 in 1,100 live births globally, and believed to be relatively common in children born to women older than 35 years. ${ }^{1,2}$ Suffering from this syndrome emanates multiple 
issues, including those of mental retardation, congenital heart disease, hearing deficits, skeletal problems and skin disorders, along with physical anomalies, majorly around the stomatognathic system, temporomandibular joint dysfunction, a small maxilla thus a flat face, delayed tooth eruption, malocclusion, dental agenesis, macroglossia, and increased occurrence of dental diseases, particularly periodontal disease. Other signs include cardiovascular and nervous system aberrations, decreased muscle tone, slanting eyes, and misshapen ears. ${ }^{1-5}$ It has been postulated in previous literature that DS individuals have a prevalence of dental caries much lower than normal individuals. ${ }^{5}$ This could be due to delayed teeth eruption, less complicated tooth morphology with less pronounced pits and fissures, and a difference of microbiota present in the oral biofilm. ${ }^{5-7}$ It has also been determined that this could be due to various environmental factors ${ }^{8}$ and a different salivary composition with altering flow rates. ${ }^{8-10}$

Saliva plays a major role in the prevention of dental caries, essentially being one of its functions. Salivary $\mathrm{pH}$ ranges between 6.2 and 7.6, maintained near neutrality with the average $\mathrm{pH}$ of saliva being 6.7. ${ }^{11}$ Human saliva contains proteins and peptides for the defense and maintenance of oral health dynamics. ${ }^{12}$ The intracellular and extracellular pathways of saliva secretion in the oral cavity make it a diagnostic medium for many diseases such as oral cancer, periodontal diseases, dental caries, oral lichen planus, and systemic diseases. ${ }^{13,14}$ Also, saliva has been proven as a detecting biofluid for viruses such as human immunodeficiency virus, human papillomavirus, hepatitis A, hepatitis C, Ebola, Zika, and the severe acute respiratory syndrome virus family. ${ }^{15,16}$ Saliva contains a host of antimicrobial factors including enzymes and antibodies such as salivary immunoglobulin $\mathrm{A}(\operatorname{sig} \mathrm{A}) .{ }^{8}$ It is reported that sIgA is one of the main immunoglobulins in the line of defense against pathogens invading mucosal surfaces, ${ }^{17}$ enhancing oral immunity by preventing microbial adhesion and bacterial colonization. ${ }^{5,8}$ Several studies have similarly demonstrated that the presence of high numbers of sIgA correlates with a low incidence of dental caries. ${ }^{17-19}$

To the best of our knowledge, however, there has been no previous review investigating the role of sIgA as an indicator for dental caries in patients of DS, as it can be a very useful biomarker for dental caries occurrence in individuals of DS moving toward prevention and oral care.

The aim of this systematic analysis is to review the studies reporting sIgA as a biomarker for dental caries incidence in DS patients and to possibly conclude whether sIgA can be used as a useful biomarker for dental caries in DS patients.

\section{Materials and Methods}

The protocol for this systematic review has not been published prior to its completion. The present systematic review and meta-analysis were performed according to the guidelines Preferred Reporting Items for Systematic Reviews and Meta-Analysis (PRISMA). ${ }^{20}$ PECO question (Patient, Exposure, Comparator, and Outcome) was applied.
A. Patients in the included studies should be between 3 and 29 years

B. Dental caries and DS

C. Stimulated saliva, whole mouth saliva, and unstimulated saliva

D. Level of sIgA levels.

\section{Search Strategies}

A systematic literature search was performed from two databases: Scopus and PubMed, searching for journal articles from January 2000 to December 2018 addressing the focused research question. For the PubMed library, the following MeSH terms were used: ("saliva"[MeSH Terms] OR “saliva”[All Fields]) AND ("down syndrome"[MeSH Terms] OR (“down”[All Fields] AND "syndrome"[All Fields]) OR “down syndrome”[All Fields]) AND IgA [All Fields]. Only articles reported in the English language were included (-Table 1). The search strategies followed the PRISMA guidelines ( $\mathbf{- F i g . 1}$ ).

\section{Study Selection}

Exclusion criteria for the included studies were case reports, review article, studies reporting incidence or prevalence, studies without statistical analysis, studies without control group, and outcome different from sIgA levels. After the removal of duplicates, studies were assessed for inclusion and exclusion criteria by two independent investigators. Any disagreement was resolved by discussion until consensus was reached.

\section{Data Extraction}

The relevant data extracted from each included study were the author's name, publication year, country, study designs, age range, biochemical analysis, sample size (number of patients with DS [cases] and number of healthy controls), mean sIgA levels in cases and controls, statistical technique applied, and results obtained (-Table $\mathbf{1}$ ). Five studies were included in meta-analysis. The articles were divided into two groups (cases and controls) in accordance with the description given by the authors. A comparative analysis was done between patients with DS and healthy controls.

\section{Quality Assessment of the Studies}

The quality of studies was assessed using the NewcastleOttawa Quality Assessment Scale (NOS) for observational studies. The following criteria were assessed: selection of study groups (diagnosed cases of DS by genetic testing, selection of cases with DS from referral centers, healthy controls from same community without any disabilities); control for confounding variable (such as socioeconomic status, medications, or any other potential factor); and outcome assessment (assessment of sIgA levels by a previously calibrated examiner; clinical evaluation of tooth decay; same evaluation method was used for case and controls; and nonresponse rate). Each item scored 1 star if sufficiently reported, and each study scored from 0 to 8 stars. 
Table 1 Study characteristics of nine included studies

\begin{tabular}{|c|c|c|c|c|c|c|c|}
\hline $\begin{array}{l}\text { Author } \\
\text { (year of } \\
\text { publication) }\end{array}$ & Country & $\begin{array}{l}\text { Study } \\
\text { design }\end{array}$ & Age range & Sample size & $\begin{array}{l}\text { Assessment of } \\
\text { salivary } \lg A\end{array}$ & Statistics & $p$-Value \\
\hline $\begin{array}{l}\text { Chaushu et al } \\
(2002)\end{array}$ & Israel & $\mathrm{CC}$ & \begin{tabular}{|l|}
$11-24 y$ \\
DS, $16-24$ \\
y controls \\
\end{tabular} & $\begin{array}{l}39 \text { ( } 29 \text { with DS, } \\
10 \text { controls) }\end{array}$ & $\begin{array}{l}\text { Salivary IgA was } \\
\text { determined by ELISA, } \\
\text { measured in } \mu \mathrm{g} / \mathrm{mL}\end{array}$ & $\begin{array}{l}\text { Wilcoxon's } \\
\text { rank-sum } \\
\text { test }\end{array}$ & NS \\
\hline $\begin{array}{l}\text { Chaushu et al } \\
(2003)\end{array}$ & Israel & CS & $11-22 y$ & $\begin{array}{l}23 \text { (14 institutionalized } \\
\text { DS subjects, } \\
9 \text { noninstitutionalized } \\
\text { DS subjects) }\end{array}$ & $\begin{array}{l}\text { Salivary IgA was } \\
\text { determined by ELISA, } \\
\text { measured in } \mu \mathrm{g} / \mathrm{mL}\end{array}$ & $\begin{array}{l}\text { Wilcoxon's } \\
\text { rank-sum } \\
\text { test }\end{array}$ & NS \\
\hline $\begin{array}{l}\text { Lee et al } \\
(2004)\end{array}$ & Korea & CC & $8-17 y$ & $\begin{array}{l}69 \text { (28 cases with DS, } \\
41 \text { matched controls) }\end{array}$ & $\begin{array}{l}\text { Salivary IgA was } \\
\text { determined by ELISA, } \\
\text { measured in } \mu \mathrm{g} / \mathrm{mL}\end{array}$ & $\begin{array}{l}\text { Student's } \\
\text { t-test }\end{array}$ & NS \\
\hline $\begin{array}{l}\text { Cogulu et al } \\
(2006)\end{array}$ & Turkey & CC & $7-12 y$ & $\begin{array}{l}143 \text { (73 with DS, } \\
70 \text { controls) }\end{array}$ & $\begin{array}{l}\text { Salivary IgA was } \\
\text { determined by radial } \\
\text { immunodiffusion tech- } \\
\text { nique, measured in mg/L }\end{array}$ & $\begin{array}{l}\text { Student's } \\
\text { t-test }\end{array}$ & Sig \\
\hline $\begin{array}{l}\text { Chaushu et al } \\
(2007)\end{array}$ & Israel & CC & Not given & $\begin{array}{l}79 \text { (40 cases with DS, } \\
39 \text { controls) }\end{array}$ & $\begin{array}{l}\text { Salivary IgA was } \\
\text { determined by ELISA, } \\
\text { measured in EU/mL }\end{array}$ & $\begin{array}{l}\text { Wilcoxon's } \\
\text { rank-sum } \\
\text { test }\end{array}$ & $\begin{array}{l}\text { Sig between YC and } \\
\text { YDS, Sig between YC } \\
\text { and OC, Sig between } \\
\text { OC and ODS }\end{array}$ \\
\hline $\begin{array}{l}\text { Areias et al } \\
(2012)\end{array}$ & Portugal & CC & $6-18 y$ & $\begin{array}{l}90 \text { (45 cases with DS, } \\
45 \text { matched sibling } \\
\text { controls) }\end{array}$ & $\begin{array}{l}\text { Salivary IgA was } \\
\text { determined by ELISA, } \\
\text { measured in } \mathrm{mg} / \mathrm{L}\end{array}$ & $\begin{array}{l}\text { Student's } \\
\text { t-test }\end{array}$ & NS \\
\hline $\begin{array}{l}\text { Fornieles et al } \\
(2014)\end{array}$ & Spain & Int & $19-26 y$ & $\begin{array}{l}40 \text { male adults with } \\
\text { DS ( } 24 \text { DS in exercising } \\
\text { group [Int], } 16 \text { DS in } \\
\text { control group) }\end{array}$ & $\begin{array}{l}\text { Salivary lgA was } \\
\text { determined by ELISA, } \\
\text { measured in } \mu \mathrm{g} / \mathrm{mL}\end{array}$ & $\begin{array}{l}\text { Two-way } \\
\text { ANOVA }\end{array}$ & $\begin{array}{l}\text { Sig in exercising } \\
\text { group, NS in control } \\
\text { group }\end{array}$ \\
\hline $\begin{array}{l}\text { Balaji et al } \\
(2016)\end{array}$ & $\begin{array}{l}\text { New } \\
\text { Zealand }\end{array}$ & CC & $2-12 y$ & $\begin{array}{l}50 \text { (20 cases with DS, } \\
10 \text { siblings, } 20 \text { parents) }\end{array}$ & $\begin{array}{l}\text { Salivary IgA was } \\
\text { determined by ELISA, } \\
\text { measured in } \mu \mathrm{g} / \mathrm{mL}\end{array}$ & ANOVA & Sig \\
\hline $\begin{array}{l}\text { Hashizume } \\
\text { et al (2017) }\end{array}$ & Brazil & CC & $6-14 y$ & $\begin{array}{l}113 \text { (61 with DS, } \\
52 \text { controls) }\end{array}$ & $\begin{array}{l}\text { Salivary IgA was } \\
\text { determined by ELISA, } \\
\text { measured in } \mu \mathrm{g} / \mathrm{mL}\end{array}$ & $\begin{array}{l}\text { Mann- } \\
\text { Whitney's } \\
\text { U test }\end{array}$ & Sig \\
\hline
\end{tabular}

Abbreviations: ANOVA, analysis of variance; CC, case-control; CS, cross-sectional; DS, Down syndrome; ELISA, enzyme-linked immunosorbent assay; Int, interventional; NS, not significant; OC, old controls; ODS, old Down syndrome; Rev, review article; Sig, significant; YC, young controls; YDS, young Down syndrome.

\section{Statistical Analysis}

The software STATA (version 14.2) was used for the meta-analysis. Meta-analyses were performed for the mean sIgA levels in cases and controls. Q-statistic and $\mathrm{I}^{2}$-statistic were used to assess the heterogeneity of the included studies. For the Q-statistic, heterogeneity was supposed statistically significant if $p \leq 0.05$. The forest plot was computed reporting weighted mean differences WMD of sIgA levels and 95\% confidence interval $(\mathrm{CI})$. The $p \leq 0.05$ was taken as statistically significant for the pooled effect. Data which were not suitable for quantitative analysis were evaluated descriptively. Moreover, funnel plot was generated to assess publication bias. If the plot was asymmetrical, then it was suggested as a publication bias.

\section{Results}

\section{Study Selection}

A total of 9 and 12 study titles and abstracts were first identified on PubMed and Scopus, respectively. After the removal of the duplicates $(n=12)$, preliminary screening of titles and abstracts was done, and two articles (one case report and one review article) were excluded because they were not meeting the eligibility criteria and were irrelevant to the focused question. A total of 10 articles were selected for full-text reading. Of these 10 studies, 1 study was further excluded because focused question was not answered in it. At final stage, all four articles were selected for qualitative synthesis (one cross-sectional study, one interventional study, and two case-control studies in which mean and standard deviation values were not reported for sIgA levels), whereas five case-control studies were included in quantitative synthesis (-Fig. 1).

\section{Study Characteristics}

All studies $(n=9)$ included in systematic review were observational studies, in which one study was cross-sectional study, ${ }^{21}$ one was interventional study, ${ }^{22}$ and seven were case-control studies. ${ }^{2,3,8,10,23-25}$ These studies were from Israel, ${ }^{21,23,24}$ Korea, ${ }^{10}$ Turkey, ${ }^{2}$ Portugal, ${ }^{3}$ Spain, ${ }^{22}$ New Zealand, ${ }^{25}$ and Brazil. ${ }^{8}$ In all of these studies, the number of participants ranged from 23 to 143 individuals with age range of 2 to 26 years. Only one study did not report the age range of the participants. ${ }^{24}$ 


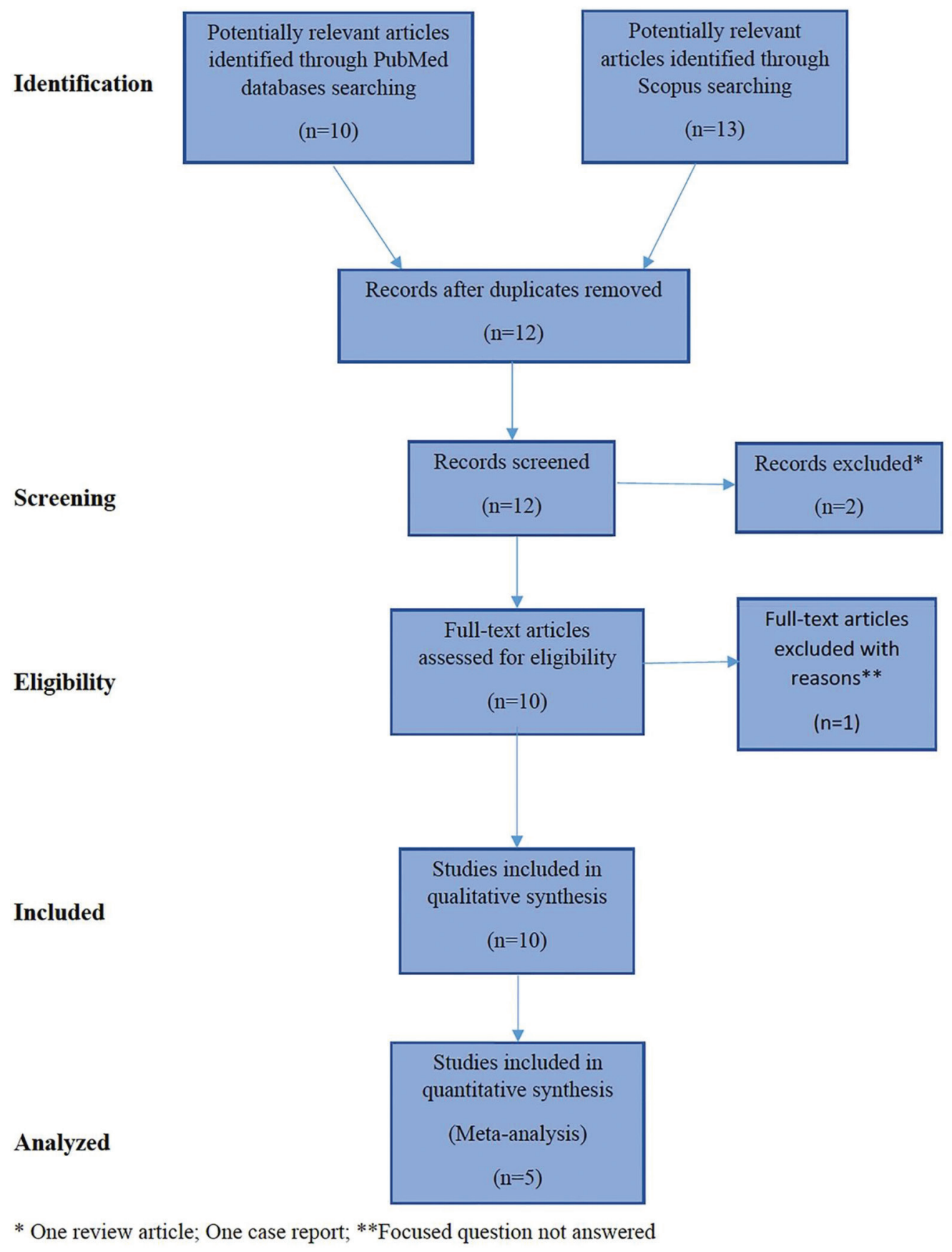

Fig. 1 Flowchart of the study.

In eight studies, sIgA levels were determined by enzymelinked immunosorbent assay and in one study by radial immunodiffusion technique. ${ }^{2}$ In two case-control studies, ${ }^{2,25}$ significant difference was found in mean sIgA levels between cases and controls $(p<0.05)$. In another case-control study, ${ }^{24}$ statistical significant difference was found in mean sIgA levels between young DS and young controls $(p<0.05)$, young controls and old controls $(p<0.05)$, and old controls and old DS patients $(p<0.05)$. In an interventional study, ${ }^{22}$ statistically significant difference was found in mean sIgA levels before and after 12-week resistance circuit training program in male adults with DS (- Table 1).

\section{Results of Literature Search}

Primary search resulted in 156 studies. After exclusion of duplicates, abstracts and titles of 145 studies were read to include studies relevant to this review. After exclusion of 132 irrelevant studies, full texts of 13 studies were read (-Fig. 1). After further exclusion of five studies, only eight studies met the inclusion criteria for this review. ${ }^{9-16}$ No studies were found in the bibliographies of the included articles during manual search. The included articles consisted of six case reports, ${ }^{10-14,16}$ a retrospective study, ${ }^{9}$ and a prospective study. ${ }^{15}$ 


\section{Main Outcome of the Studies}

The comparison of salivary levels of IgA in DS patients as compared with the healthy controls is shown in - Table 2. The pooled MDs of sIgA was $0.433 \mu \mathrm{g} / \mathrm{mL}$ (95\% CI: -0.160 to 1.026). A high degree of heterogeneity was found among both the groups of $85.6 \%$ and a significant associated $p$-value of $<0.05$. The forest plot showed several nonoverlapping CIs, which also indicated the heterogeneity of the studies (-Fig. 2).

\section{Quality Assessment of Included Studies}

The assessment of the quality of the studies was done on the $\mathrm{NOS}^{26}$ ranging from four to six points. A mean score of 5 was achieved for the included studies ( - Tables 2 and $\mathbf{3}$ ).

\section{Discussion}

The present analysis was undertaken to explicate on the investigation and possible determination of sIgA as a useful biomarker for dental caries in DS children. Various studies have predicated a lower prevalence of dental caries in DS children as compared with their normal counterparts, ${ }^{2-5,8,17,25}$ included in this analysis..$^{2-4,8,10}$ The occurrence of dental caries and levels of sIgA in children with DS is ascertained, compared with matching controls to balance for confounders.

It has been hypothesized that many environmental factors come into play for the suggested lower prevalence of dental caries in DS children, including a delayed eruption of teeth, congenital oligodontia, a diet differing in sugary components compared with normal individuals, and a contrasting salivary composition. ${ }^{2}$ A variety of environmental factors come into play which can alter the salivary physiology, such as oral hygiene and dietary habits. ${ }^{8}$

Immune defenses against dental caries may be enhanced by the presence of increased amounts of sIgA in DS children. Studies have tried to associate the presence of SIgA as a significant factor for a relatively lower frequency of occurrence of dental caries in DS patients. ${ }^{27,28}$ IgA antibodies within the saliva may tend to create a neutralizing effect on the toxins and enzymes thus inactivating them, hindering the adherence of bacteria, ${ }^{8}$ creating an inhibition of streptococcal accretion on the tooth surfaces ${ }^{29}$ necessary to kick start the carious process. ${ }^{30}$ Variable salivary flow rates in DS individuals as compared with their normal counterparts also add to a rather low prevalence of dental caries. Coupled with certain eruptive and morphologic traits pertaining to teeth imminent in DS patients; late eruption in the oral cavity, less pronounced pits and fissures; and the incidence of dental caries is thus found to be low. ${ }^{3,31}$

As apparent in our article search, a restricted number of studies were eligible according to our eligibility criteria, highlighting the limited amount of research that has been done focusing on this topic. Adding to that, the small sample sizes that have been used in the studies for evaluating the occurrence of dental caries in DS patients ultimately show insubstantial conclusive evidence of using sIgA as a biomarker for dental caries.

It has been hypothesized that sIgA present in saliva hinders the adherence of bacteria causative of dental caries to the tooth surface, neutralizing the extracellular enzymes in the process as well. ${ }^{2,30}$ Moreover, Lee et $\mathrm{al}^{10}$ and Areias et $\mathrm{al}^{3}$ also found increased levels of Streptococcus mutans-specific sIgA in DS patients as compared with their controls. Areias et $\mathrm{al}^{3}$ also found low counts of $S$. mutans in DS children when compared with their sibling controls. sIgA usually plays a crucial role in protecting the structures in the oral cavity including the mucosa against a probable bacterial invasion. Doing so, it also protects against dental caries and diseases of the periodontium. ${ }^{25}$

Heterogeneity across results is marked with a total heterogeneity of $85.6 \%(p=0.001)$. Even though studies posit the hypothesis that high sIgA levels reduce the occurrence of caries,,$^{2-5,8,17,25}$ Lee et $\mathrm{al}^{10}{ }^{10}$ among other studies, ${ }^{32,33}$ nonetheless, stated the opposite that sIgA levels have no significant impact on the incidence of caries in DS individuals. This is believed to be based on the different age groups and ranges assessed within the differing studies of DS participants. As also reported by Balaji et al, ${ }^{25}$ children with DS and their parents had higher amounts of sIgA levels as compared with siblings of the DS participants, showing a

Table 2 Weighted mean difference of salivary IgA levels in cases and controls of studies included in meta-analysis

\begin{tabular}{|c|c|c|c|c|c|c|c|c|}
\hline \multirow[t]{2}{*}{ No. } & \multirow[t]{2}{*}{ Study ID } & \multicolumn{3}{|c|}{ Cases } & \multicolumn{3}{|c|}{ Controls } & \multirow{2}{*}{$\begin{array}{l}\text { Weighted mean difference IV, } \\
\text { random, } 95 \% \mathrm{Cl}\end{array}$} \\
\hline & & $n$ & Mean & SD & $n$ & Mean & SD & \\
\hline 1 & \multirow[t]{2}{*}{ Balaji et al (2016) } & \multirow[t]{2}{*}{19} & \multirow[t]{2}{*}{95.1} & \multirow[t]{2}{*}{48.4} & 20 & 92.5 & 46.5 & $0.05(-0.57,0.68)$ \\
\hline 2 & & & & & 10 & 48.3 & 25.7 & $1.11(0.29,1.93)$ \\
\hline 3 & Chaushu et al (2003) & 14 & 112 & 34 & 9 & 121 & 30 & $-0.28(-1.12,0.56)$ \\
\hline 4 & Lee et al (2004) & 19 & 24 & 10 & 41 & 22 & 6 & $0.27(-0.28,-0.81)$ \\
\hline 5 & Areias et al (2012) & 45 & 0.08 & 0.04 & 45 & 0.08 & 0.04 & $0.00(-0.41,-0.41)$ \\
\hline \multirow[t]{3}{*}{6} & Cogulu et al (2006) & 73 & 0.37 & 0.24 & 70 & 0.13 & 0.06 & $1.36(1.00,1.72)$ \\
\hline & Total & 170 & & & 195 & & & $0.43(-0.16,1.03)$ \\
\hline & \multicolumn{8}{|c|}{ Total heterogeneity: $I^{2}=85.6 \%, p=0.001$} \\
\hline
\end{tabular}

Abbreviations: $\mathrm{Cl}$, confidence interval; IV, independent variable; SD, standard deviation. 


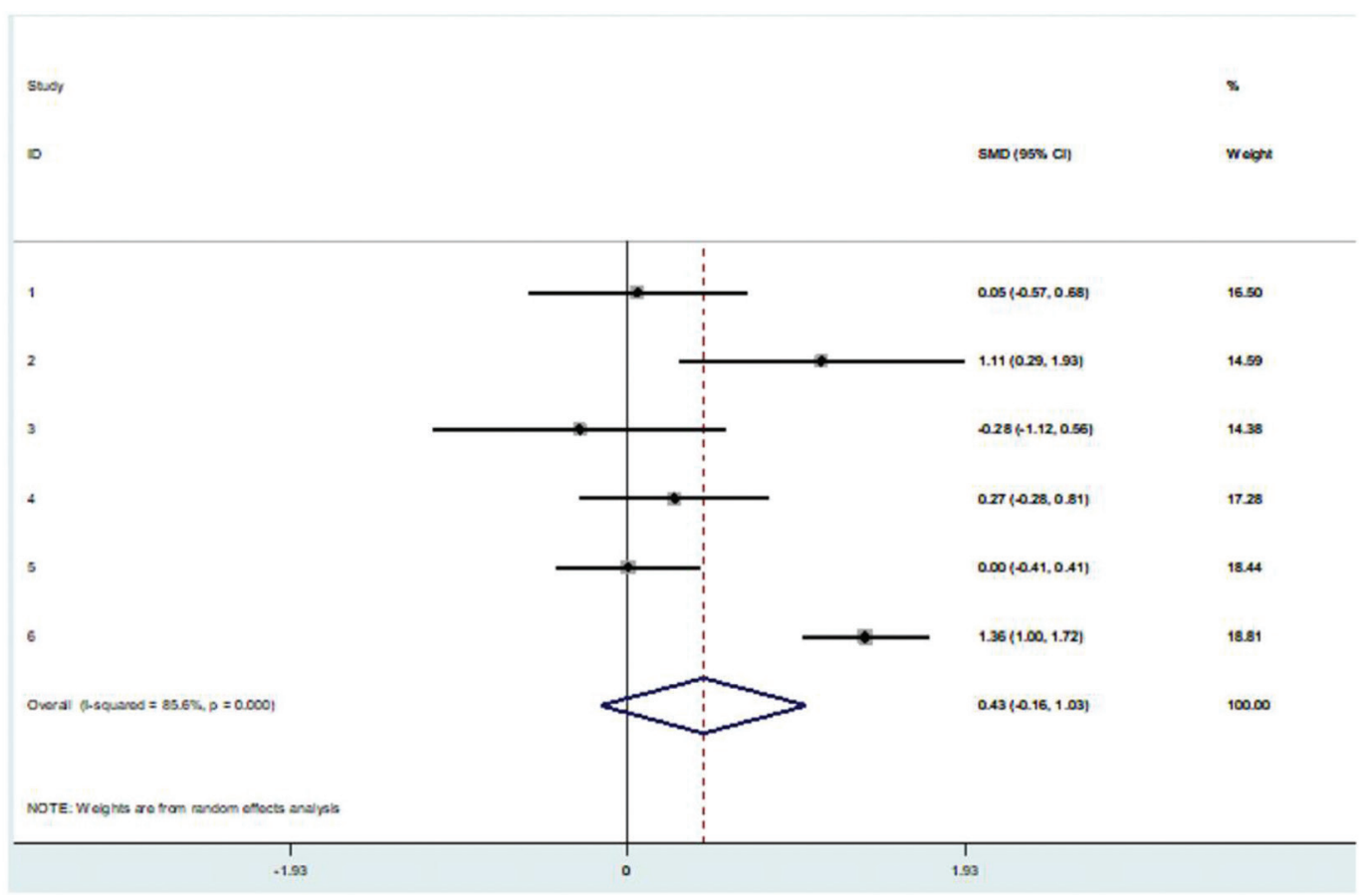

Fig. 2 Forest plot of random effects of salivary immunoglobulin A levels in Down syndrome patients versus controls. Study ID number in this figure correlates with No. column in Table 2 for understanding.

Table 3 Quality assessment of included studies

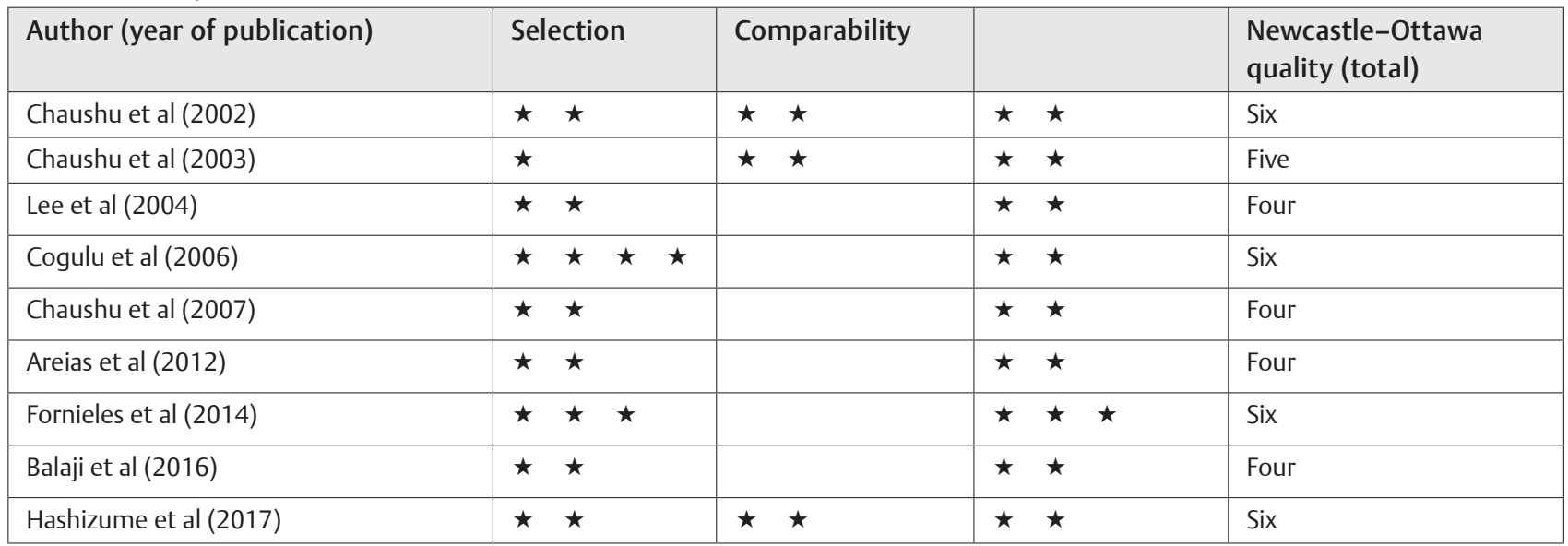

consequential effect of a wide age gap on the sIgA secretion concentrations.

Marked heterogeneity and low samples in studies which were included in the quantitative synthesis limit to draw any significant conclusive evidence of sIgA as an identifying factor for dental caries in patients with DS. Many other confounding factors are hypothesized to be possible not limited to environmental factors, oral hygiene measures, and differing dietary habits of DS patients compared with their healthy counterparts.

\section{Conclusion}

Patients with DS are believed to be at a higher risk of dental caries due to malocclusion and the quality of lifestyle that is understandably compromised compared with healthy children. However, the reason for the low occurrence of dental caries is not very well understood in DS patients, despite availability of a finite amount of literature. Further, well-designed and long-term clinical studies and translational research are required before benchmarking sIgA as a useful biomarker for dental caries in DS patients. There is a dire need of more longitudinal clinical studies on DS patient saliva with preferably large sample sizes requiring advanced molecular attention.

Funding

None.

\section{Conflict of Interest}

None declared. 


\section{References}

1 Human Genomics in Global Health. Genes and human diseases Available at: https://www.who.int/genomics/public/ geneticdiseases/en/index1.html. Accessed November 17, 2019

2 Cogulu D, Sabah E, Kutukculer N, Ozkinay F. Evaluation of the relationship between caries indices and salivary secretory IgA, salivary $\mathrm{pH}$, buffering capacity and flow rate in children with Down's syndrome. Arch Oral Biol 2006;51(1):23-28

3 Areias C, Sampaio-Maia B, Pereira MdeL, et al. Reduced salivary flow and colonization by mutans streptococci in children with Down syndrome. Clinics (São Paulo) 2012;67(9):1007-1011

4 Cornejo LS, Zak GA, de Cattoni STD, Calamari SE, Azcurra AI, Battellino LJ. Bucodental health condition in patients with Down syndrome of Cordoba City, Argentina. Acta Odontol Latinoam 1996;9(2):65-79

5 Soham B, Srilatha KT, Seema D. Salivary characteristics of Down's syndrome children- a review. J Oral Hyg Heal 2016;4:201

6 Normastura A, Norhayani Z, Azizah Y, Malaysiana MK-S. Saliva and dental caries in Down syndrome children. Sains Malaysiana 2013;42(1):59-63

7 Castilho ARF, Pardi V, Pereira CV. Caries prevalence, level of mutans streptococci, salivary flow rate, and buffering capacity in subjects with Down syndrome. Braz J Oral Sci 2007;6(21): 1331-1336

8 Hashizume LN, Schwertner C, Moreira MJS, Coitinho AS, Faccini LS. Salivary secretory IgA concentration and dental caries in children with Down syndrome. Spec Care Dentist 2017;37(3):115-119

9 Morinushi T, Lopatin DE, Van Poperin N. The relationship between gingivitis and the serum antibodies to the microbiota associated with periodontal disease in children with Down's syndrome. J Periodontol 1997;68(7):626-631

10 Lee SR, Kwon HK, Song KB, Choi YH. Dental caries and salivary immunoglobulin A in Down syndrome children. J Paediatr Child Health 2004;40(9-10):530-533

11 Baliga S, Muglikar S, Kale R. Salivary pH: a diagnostic biomarker. J Indian Soc Periodontol 2013;17(4):461-465

12 Khurshid Z, Naseem M, Sheikh Z, Najeeb S, Shahab S, Zafar MS. Oral antimicrobial peptides: types and role in the oral cavity. Saudi Pharm J 2016;24(5):515-524

13 Khurshid Z, Zafar MS, Khan RS, Najeeb S, Slowey PD, Rehman IU. Role of salivary biomarkers in oral cancer detection. Adv Clin Chem 2018;86:23-70

14 Shazam H, Shaikh F, Hussain Z, Majeed MM, Khan S, Khurshid Z. Evaluation of osteocalcin levels in saliva of periodontitis patients and their correlation with the disease severity: a cross-sectional study. Eur J Dent 2020; 14(03): 352-359

15 Hamid H, Khurshid Z, Adanir N, Zafar MS, Zohaib S. COVID-19 pandemic and role of human saliva as a testing biofluid in point-of-care technology. Eur J Dent 2020. DOI: 10.1055/s-0040-1713020

16 Khurshid Z, Zafar M, Khan E, Mali M, Latif M. Human saliva can be a diagnostic tool for Zika virus detection. J Infect Public Health 2019;12(5):601-604

17 Ranadheer E, Nayak UA, Reddy NV, Rao VA. The relationship between salivary IgA levels and dental caries in children. J Indian Soc Pedod Prev Dent 2011;29(2):106-112

18 Katz J, Harmon CC, Buckner GP, Richardson GJ, Russell MW, Michalek SM. Protective salivary immunoglobulin A responses against Streptococcus mutans infection after intranasal immunization with $S$. mutans antigen I/II coupled to the B subunit of cholera toxin. Infect Immun 1993;61(5):1964-1971

19 Fontana M, Gfell LE, Gregory RL. Characterization of preparations enriched for. Streptococcus mutans Clin Diagn Lab Immunol 1995;2(6):719-725

20 Moher D, Liberati A, Tetzlaff J, Altman DG; PRISMA Group. Preferred reporting items for systematic reviews and meta-analyses: the PRISMA statement. BMJ 2009;339:b2535

21 Chaushu S, Yefe Nof E, Becker A, Shapira J, Chaushu G. Parotid salivary immunoglobulins, recurrent respiratory tract infections and gingival health in institutionalized and non-institutionalized subjects with Down's syndrome. J Intellect Disabil Res 2003;47(Pt 2) :101-107

22 Fornieles G, Rosety MA, Elosegui S, et al. Salivary testosterone and immunoglobulin A were increased by resistance training in adults with Down syndrome. Braz J Med Biol Res 2014;47(4):345-348

23 Chaushu S, Yefenof E, Becker A, Shapira J, Chaushu G. Severe impairment of secretory Ig production in parotid saliva of Down syndrome individuals. J Dent Res 2002;81(5):308-312

24 Chaushu S, Chaushu G, Zigmond M, et al. Age-dependent deficiency in saliva and salivary antibodies secretion in Down's syndrome. Arch Oral Biol 2007;52(11):1088-1096

25 Balaji K, Milne TJ, Drummond BK, Cullinan MP, Coates DE. A comparison of salivary IgA in children with Down syndrome and their family members. Arch Oral Biol 2016;67:39-45

26 Wells GA, Shea B, O'Connell D, et al. NewCastle-Ottawa Quality Assessment Scale-Case Control Studies. Namibia: Belia Vida Centre; 2017

27 Nogueira RD, Alves AC, Napimoga MH, Smith DJ, Mattos-Graner RO. Characterization of salivary immunoglobulin A responses in children heavily exposed to the oral bacterium Streptococcus mutans: influence of specific antigen recognition in infection. Infect Immun 2005;73(9):5675-5684

28 Gregory RL, Michalek SM, Filler SJ, Mestecky J, McGhee JR. Prevention of Streptococcus mutans colonization by salivary IgA antibodies. J Clin Immunol 1985;5(1):55-62. Doi:10.1007/ BF00915169

29 Takeuchi H, Kanehisa J, Hori Y, et al. Periodontal disease and resistance factor. III. Localization of secretory IgA and serum IgA in the inflamed human gingiva. Nihon Shishubyo Gakkai Kaishi 1982;24(3):416-420

30 Hajishengallis G, Nikolova E, Russell MW. Inhibition of Streptococcus mutans adherence to saliva-coated hydroxyapatite by human secretory immunoglobulin A (S-IgA) antibodies to cell surface protein antigen I/II: reversal by IgAl protease cleavage. Infect Immun 1992;60(12):5057-5064

31 Orner G. Dental caries experience among children with Down's syndrome and their sibs. Arch Oral Biol 1975;20(10):627-634

32 Jalil RA, Ashley FP, Wilson RF. The relationship between 48-h dental plaque accumulation in young human adults and the concentrations of hypothiocyanite, 'free' and 'total' lysozyme, lactoferrin and secretory immunoglobulin A in saliva. Arch Ora Biol 1992;37(1):23-28. Doi:10.1016/0003-9969(92)90148-2.

33 Gregory RL, Michalek SM, Filler SJ, Mestecky J, McGhee JR. Prevention of Streptococcus mutans colonization by salivary IgA antibodies. J Clin Immunol 1985;5(1):55-62 